\title{
French translation of the Multidimensional Pain Inventory: L'inventaire multidimensionnel de la douleur
}

\author{
Simon Laliberté $\mathrm{PhD}^{1,2}$, Julie Lamoureux $\mathrm{DMD} \mathrm{MSc}^{3}$, Michael JL Sullivan $\mathrm{PhD}^{4}$, Jean-Marc Miller $\mathrm{MPs}^{2}$,
} Julie Charron $\mathrm{PhD}^{2}$, Donald Bouthillier $\mathrm{PhD}^{5}$

S Laliberté, J Lamoureux, MJL Sullivan, J-M Miller, J Charron, D Bouthillier. French translation of the Multidimensional Pain Inventory: L'inventaire multidimensionnel de la douleur. Pain Res Manage 2008;13(6):497-505.

BACKGROUND: The Multidimensional Pain Inventory (MPI) is a widely used tool in the evaluation of pain conditions. This questionnaire has been translated and validated in multiple languages. However, there is no validated French-language version available for clinicians and researchers interested in evaluating people living with pain.

OBJECTIVES: The main objective of the present project was to make available a validated French-language evaluation tool for the cognitive, behavioural and emotional aspects of pain.

METHODS: Following a reverse translation of the MPI, a Frenchlanguage version of the questionnaire, the Inventaire multidimensionnel de la douleur, that was presented to 227 participants living with chronic pain, was obtained. These participants were all involved in a rehabilitation program in four different settings. A series of exploratory and confirmatory factor analyses was executed.

RESULTS AND CONCLUSIONS: Although three items were removed from the original version of the MPI, the three sections of the Inventaire multidimensionnel de la douleur had good psychometric properties. The results concerning the questionnaire's structure were very similar to those obtained with the original tool and during its translation into other languages. People wishing to evaluate pain in French-speaking populations now have access to a French-language version of the MPI.

\section{La traduction française du Multidimensional Pain Inventory : L'inventaire multidimensionnel de la douleur}

HISTORIQUE : Le Multidimensional Pain Inventory (MPI) est un outil largement utilisé pour évaluer les troubles de douleur. Ce questionnaire est traduit et validé dans de nombreuses langues, mais il n'existe pas de version française validée pour les cliniciens et les chercheurs intéressés à évaluer les personnes qui vivent avec la douleur.

OBJECTIFS : Le principal objectif du présent projet consistait à diffuser un outil d'évaluation français validé des aspects cognitifs, comportementaux et affectifs de la douleur.

MÉTHODOLOGIE : Après la traduction du MPI, une version française du questionnaire, l'Inventaire multidimensionnel de la douleur, a été présentée à 227 participants souffrant de douleur chronique. Ces participants étaient inscrits à un programme de réadaptation dans quatre établissements différents. Les auteurs ont procédé à une série d'analyses des facteurs exploratoires et confirmatoires.

RÉSULTATS ET CONCLUSION : Même si trois points ont été retirés de la version originale du MPI, les trois parties de l'inventaire multidimensionnel de la douleur comportaient de bonnes caractéristiques psychométriques. Les résultats portant sur la structure du questionnaire étaient très similaires à ceux obtenus avec l'outil original et pendant sa traduction dans d'autres langues. Les personnes désirant évaluer la douleur au sein de populations francophones ont désormais accès à une version française du MPI.

Key Words: Evaluation; French language; MPI; Pain; Questionnaire

The Multidimensional Pain Inventory (MPI) scale (1) was 1 developed based on cognitive-behavioural concepts applied to chronic pain (2), which allows researchers to evaluate the cognitive, behavioural and emotional aspects of pain (3). The tool is an integral part of the Multiaxial Assessment of Pain and enables individuals with pain to be classified according to psychosocial and behavioural factors rather than factors related to their physical injury alone.

The MPI stands out for being easy to administer, corresponding closely with a cognitive-behavioural perspective in terms of theory and being psychometrically robust (1). It has good psychometric properties (reliability and validity [1]) and appears to be sensitive to clinical changes following treatment. Moreover, this tool has been used with a variety of pain conditions (fibromyalgia [4], whiplash-associated disorder [5], cancer [6] and chest pain [7]). Of the five tools most commonly used for evaluating people with chronic pain, the MPI is one of the two in this group specifically designed for a pain population (8), the other being the McGill Pain Questionnaire. It is also recognized as one of the best instruments for the multidimensional assessment of pain $(5,9)$.

The MPI has been validated in English (1) and validated translations of the scale have been completed in the following languages - German (10), Dutch (2), Italian (11) and Swedish (12). No validated French translations have been published. Translating a validated instrument into another language enables us to compare different populations in terms of the results inherent to these instruments (eg, evaluation or

\footnotetext{
${ }^{1}$ Cliniques d'Évaluation et de Réadaptation; ${ }^{2}$ Centre de réadaptation Lucie-Bruneau; ${ }^{3}$ Department of Social and Preventive Medicine, Université de Montréal; ${ }^{4} \mathrm{McGill}$ University; ${ }^{5} \mathrm{Hôpital} \mathrm{du} \mathrm{Sacré-Cour} \mathrm{de} \mathrm{Montréal,} \mathrm{Montreal,} \mathrm{Quebec}$

Correspondence, reprints and copies of the questionnaire: Dr Simon Laliberté, Cliniques d'Évaluation et de Réadaptation, 6494 Beaubien East,

Montreal, Quebec H1M 1A9. Telephone 514-254-7915, fax 514-254-3406, e-mail s.laliberte@evaluation-readaptation.com
} 
treatments). However, we cannot assume that a translated version retains all the psychometric properties of the original instrument. The translation must comply with certain criteria (13) and an assessment of the psychometric properties of a translation is always required (12).

The MPI comprises 52 items (1) divided into three sections, allowing for evaluation of the impact of chronic pain on various aspects of the lives of people living with it. Section 1 evaluates their experience with pain and comprises five factors (pain interference, support, pain severity, life control and affective distress). Section 2 assesses participants' perception of the support they receive from their significant other. This section has three factors (negative responses, solicitous responses and distractive responses). Section 3 evaluates daily activities and lists four factors (household chores, outdoor work, activities away from home and social activities). Calculating the mean result of these four scales gives us a measurement of general activity level.

The objective of the present study was therefore to translate the MPI accurately into French to obtain a validated version with good psychometric properties.

\section{Translation process}

\section{METHODS}

Procedure and participants: A translator translated the MPI from English into French; this version was then retranslated from French into English by another translator (back translation [13]). The accuracy of the translation was assessed by comparing the new English version with the original English text. The two translators and a language expert (professional translator) then met as a committee to establish a preliminary French-language version, taking care to avoid word-for-word translation and ensure that this translation faithfully conveyed the meaning of the original items.

To ensure there were no comprehension issues, eight participants from the target clinical population (education [mean \pm SD] $12.3 \pm 3.2$ years; duration of pain $24.7 \pm 31.5$ months) identified passages in this preliminary version that they did not understand. Four professionals working with this population also commented on the choice of words. An experimental version was then produced, in which instructions and items pinpointed by various people as being unclear were modified.

To test the reliability of this experimental version of the questionnaire, it was administered to participants living with chronic pain ( $\mathrm{n}=24 ; 17$ men and seven women). The educational level of these participants $(11.9 \pm 3.0$ years) was comparable with a high school diploma and the mean duration of pain (28.9 \pm 47.0 months) showed that their condition was chronic. Most of them had been injured in an occupational accident $(n=17 ; 70.8 \%)$ and suffered primarily from back pain $(n=18$; $75 \%)$.

Results: By comparing the internal consistency indexes (alpha) of the original scale (1) with those of the experimental version, factors that did not appear to reach the same degree of homogeneity were identified. Changes were then made to the experimental version. In section 1 , which contained internal reliability coefficients (alpha) ranging from 0.25 to 0.96 , one item was modified in the pain interference factor and one in the affective distress factor. In section 2, one item was altered in the negative responses factor and one in the distractive responses factor; the internal consistency coefficients (alpha) ranged from 0.38 to 0.90 . In section 3 , the internal consistency coefficients (alpha) ranged from -0.69 to 0.72 . The activities away from home factor required substantial changes; three of four items were modified. Two items were altered in the social activities factor. Once this version was complete, the Inventaire multidimensionnel de la douleur (IMD) questionnaire was validated.

\section{Validation process}

Participants: Data were available for 227 individuals living with chronic pain who completed the IMD. These participants came from three rehabilitation settings treating a chronic pain population. Altogether, there were 114 men (50.2\%) and 113 women (49.8\%); no specific sampling method was used. The mean age of the sample was $42.4 \pm 9.8$ years (range 19 to 64 years). The sample represented a variety of people living with chronic pain. Participants had suffered pain for a mean duration of $42.7 \pm 46.9$ months. Most patients $(66.5 \%)$ had back pain, $18.1 \%$ had neck or shoulder pain, and $11.0 \%$ had lower limb pain. The other patients had facial or head pain $(n=2,0.9 \%)$, thoracic pain $(n=2,0.9 \%)$ or abdominal pain $(n=1,0.4 \%)$. Five patients did not identify a specific area for their pain.

Statistical analyses: First, a series of exploratory factor analyses (FAs) were performed in SPSS (version 12.0; SPSS Inc, USA) to determine whether the correlational structure among the translated items would allow for multidimensional modelling that resembled the structure proposed in the literature for the MPI (1). Bartlett's test of sphericity and the Kaiser-MeyerOklin measure of sampling adequacy were used to verify whether the data were appropriate for FA. The number of extracted factors was set to be the same as the original factor structure for each section separately. If problems appeared with the number of potential factors, an eigenvalue greater than 1.0 was used as the factor extraction criterion. The analyses were performed using principal axis factoring extraction followed by an oblique rotation.

To follow the modelling approach proposed by the authors, three separate confirmatory FAs were performed after the exploratory FA, one for each of the three sections of the IMD, using LISREL (version 8.5; Scientific Software International, USA). Because of the ordinal nature of the item responses, the polychoric correlation matrix (as well as the asymptotic covariance matrix) was first computed in PRELIS and referred to in the LISREL syntax. The estimation method theoretically appropriate for this kind of analysis is weighted least squares (WLS [14]). For each analysis, a few models were compared for fit. In ascending order of factorial complexity, the models included the unifactorial solution, ie, only one factor for all items; the model with the same number of independent (orthogonal) factors as reported in the literature; the model with the same number of correlated (oblique) factors as reported in the literature; and finally, if appropriate, a model in which some items were allowed to load on more than one factor as suggested by the highest modification indexes (MIs) for lambda $x$. As measures of fit, adjusted goodness of fit, normed fit indexes (NFI) and non-normed fit indexes (NNFI) were used; a minimal satisfactory fit was set to at least 0.9 for these indexes (15). Standardized root mean square residuals (RMR) 
TABLE 1

Item composition of the Inventaire multidimensionel de la douleur, section 1, with factor loading

Factor

Factors and items loading

Pain interference $(4.66 \pm 0.97, \alpha=0.836)$

In general, how much does your pain problem interfere with your day to day activities? En général, à quel point votre douleur nuit-elle à vos activités de tous les jours?

Since the time you developed a pain problem, how much has your pain changed your ability to work? Depuis que votre problème de douleur a débuté, à quel point a-t-il changé votre capacité à travailler?

How much has your pain changed the amount of satisfaction or enjoyment you get from participating in social and recreational activities? À quel point votre douleur a-t-elle changé la satisfaction ou le plaisir que vous retirez des activités sociales ou récréatives?

How much has your pain changed your ability to participate in recreational and other social activities? À quel point votre douleur a-t-elle changé votre capacité à prendre part à des activités sociales ou récréatives?

How much has your pain changed the amount of satisfaction you get from family-related activities? À quel point votre douleur a-t-elle changé la satisfaction ou le plaisir que vous retirez de vos activités familiales?

How much has your pain changed your marriage and other family relationships? À quel point votre douleur a-t-elle changé vos relations avec votre conjoint, et avec votre famille?

How much has your pain changed the amount of satisfaction or enjoyment you get from work? À quel point votre douleur a-t-elle changé la satisfaction ou le plaisir que vous retirez de votre travail?

How much has your pain changed your ability to do household chores? À quel point votre douleur a-t-elle changé votre capacité à effectuer des travaux ménagers?

How much has your pain changed your friendships with people other than your family? À quel point votre douleur a-t-elle changé vos relations d'amitié avec des personnes autres que les membres de votre famille?

Support (4.42 $\pm 1.65, \alpha=0.877)$

How supportive or helpful is your spouse (significant other) to you in relation to your pain? À quel point votre conjoint vous soutient-il ou vous appuie$t$-il en ce qui a trait à votre douleur?

How attentive is your spouse (significant other) to your pain problem? À quel point votre conjoint est-il attentif à votre problème de douleur?

Pain severity $(4.37 \pm 1.05, \alpha=0.843)$

Rate the level of your pain at the present moment. Évaluez le niveau de votre douleur en ce moment.

0.721

0.743

0.836

0.834

0.869

0.507

0.605

0.758

0.545

On the average, how severe has your pain been during the last week? En moyenne, à quel point évaluez-vous l'intensité de votre douleur durant la dernière semaine?

How much suffering do you experience because of your pain? À quel point souffrez-vous à cause de votre douleur?

Life control $(3.12 \pm 1.32, \alpha=0.668)$

During the past week how much control do you feel that you have had over your life? À quel point avez-vous l'impression d'avoir eu le contrôle sur votre vie, durant la dernière semaine?

During the past week how much do you feel that you've been able to deal with your problems? À quel point avez-vous l'impression d'avoir été en mesure de gérer vos problèmes durant la dernière semaine?

Affective distress $(3.55 \pm 1.26, \alpha=0.783)$

Rate your overall mood during the past week. Évaluez votre humeur générale durant la dernière semaine.

During the past week how irritable have you been? Durant la dernière semaine, à quel point avez-vous été irritable?

During the past week how tense or anxious have you been? Durant la dernière semaine, à quel point avez-vous été tendu ou anxieux?

Factor scores presented as mean $\pm S D$

were also considered and a value as close as possible to or lower than 0.05 was considered to show satisfactory fit. All fit indexes were compared among models to determine which model had the best balance of fit to parsimony. In the case of unsatisfactory fit, MIs were examined. The only MIs considered in the present study were for factor loadings (lambda $x$ in LISREL) and these MIs had to have a theoretical basis for modifying the model. Squared multiple correlations $\left(\mathrm{R}^{2}\right)$ were also considered for each variable. $R^{2}$ is an estimation of the use of the model in explaining the common variability of items. Internal consistency for each factor was measured by computing Cronbach's alpha coefficients. The correlation coefficients between factor scores were compared with those reported in the literature (14). The comparison was assessed by visual inspection of the correlation coefficients.

FAs on IMD section 1

\section{RESULTS}

The exploratory FA indicated that in a five-factor oblique solution, all 20 items had acceptable communalities. This solution explained more than $59 \%$ of the common variance. When confirming the model of section 1 items using LISREL, it was found that the asymptotic variances matrix could not be inverted, an essential prerequisite to the WLS method of extraction. The item 'How worried is your spouse (significant other) about you in relation to your pain problems?' appeared to be the root of the problem. This item is truncated later in the text to make it easier for the reader. The full item appears in the questionnaire. When this item was removed, the problem with the asymptotic covariance matrix was eliminated but the solution could not converge after 500 iterations; ie, there was no unique solution.

Because removing the item 'How worried is your spouse [...]' is justifiable (see Discussion), confirmatory FA was performed on the first section without this item. The WLS method was still not feasible so the maximum likelihood approach was used. Table 1 shows the factor loadings for the oblique model (with 19 items), the one closest to that reported in the literature $(2,11,16)$. The items 'How much has your pain 


\section{TABLE 2}

Item composition of the Inventaire multidimensionnel de la douleur, section 2, with factor loading

\begin{tabular}{|c|c|}
\hline Factors and items & Factor loading \\
\hline \multicolumn{2}{|l|}{ Negative responses $(1.51 \pm 1.67, \alpha=0.914)$} \\
\hline Expresses irritation at me. Exprime de l'irritabilité à mon endroit. & 0.924 \\
\hline Expresses frustration at me. Exprime de la frustration envers moi. & 0.949 \\
\hline Expresses anger at me. Exprime de la colère à mon endroit. & 0.963 \\
\hline \multicolumn{2}{|l|}{ Solicitous responses $(3.37 \pm 1.57, \alpha=0.842)$} \\
\hline Asks me what he/she can do to help. Me demande ce qu'il peut faire pour aider. & 0.880 \\
\hline Takes over my jobs or duties. Se charge de ma partie des tâches ou responsabilités. & 0.879 \\
\hline Tries to get me to rest. Essaie de faire en sorte que je me repose. & 0.916 \\
\hline Gets me some pain medication. Va me chercher des médicaments contre la douleur. & 0.819 \\
\hline Gets me something to eat or drink. Va me chercher quelque chose à manger ou à boire. & 0.892 \\
\hline Turns on the TV to take my mind off my pain. Ouvre la télévision pour me distraire de ma douleur. & 0.804 \\
\hline \multicolumn{2}{|l|}{ Distractive responses $(3.18 \pm 1.57, \alpha=0.700)$} \\
\hline Talks to me about something else to take my mind off the pain. Me fait la conversation pour me distraire de la douleur. & 0.844 \\
\hline Tries to involve me in some activity. M'incite à prendre part à une activité. & 0.655 \\
\hline Encourages me to work on a hobby. M'encourage à m'adonner à un passe-temps. & 0.800 \\
\hline
\end{tabular}

Factor scores presented as mean \pm SD. TV Television

changed your marriage and other family relationships?' and 'How much has your pain changed your friendships with people other than your family?' had the lowest coefficients of determination $\left(\mathrm{R}^{2}\right)$. In the exploratory analysis, it was also suggested that these items could belong to the affective distress factor instead of the pain interference factor. The highest MI for lambda $x$ indicated that the item 'How much has your pain changed your marriage and other family relationships?' should load on the affective distress factor. The factorial correlation coefficients between factor scores were small to moderate (absolute values ranged between 0.024 and 0.695). The highest correlation coefficient (0.695) was observed between the pain interference and pain severity factors. Note that factorial correlation coefficients may differ from correlation coefficients (Table 4) because they are calculated differently. The factorial correlations computed in LISREL are computed between factor scores; these scores are computed from the regression equations resulting from the factor analysis. The correlations in Table 4 are computed between ad hoc scores obtained by averaging the items of a factor. This explains the differences in relative sizes and values of the correlations. The support factor had low factorial correlation coefficients $(0.024$ to 0.240$)$ with the other four factors suggesting, as pointed out by Deisinger et al (17), that this factor could belong to another concept of pain. Deisinger et al's solution is to add this factor to the solicitous responses and distractive responses factors in section 2 of the MPI. Such a relation could not be identified with this type of analysis because the three sections were analyzed separately.

Cronbach's alpha coefficients were moderate to high. For the 19 items taken together (unifactorial structure), the alpha was computed to be 0.802 . Note that a high Cronbach alpha coefficient does not indicate that items are one-dimensional. It is an indication of the reliability of the factor in its entirety. In the five-factor solution for the pain interference factor, the alpha was 0.836 ; for the support factor, 0.877 ; for the pain severity factor, 0.843 ; for the life control factor, 0.668 ; and for the affective distress factor, 0.783 . Although the last two factors had lower internal consistencies, the alpha coefficients were still acceptable.
The fit indexes suggest that a five-factor oblique model (with or without crossloadings) is acceptable when the item 'How worried is your spouse [...]' is not included in the analysis, which was not the case when the item was included. The NFI and NNFI were above 0.9 and the standardized RMR was 0.08 . The oblique solution without crossloadings should be preferred for its simplicity. For section 1 of the IMD, the item 'How worried is your spouse [...]' is removed and a five-factor solution is suggested.

\section{FAs on IMD section 2}

The exploratory FA indicated that in a three-factor oblique solution, two of the 14 items had low communalities ('Ignores me' had a communality of 0.086 and 'Reads to me' had a communality of 0.065 ). This solution explained almost $51 \%$ of the common variance. Because removing the items 'Ignores me' and 'Reads to me' can also be justified (see Discussion), confirmatory FA was performed on section 2 of the IMD without these two items. Table 2 presents the factor loadings from the confirmatory FA for the oblique model without crossloadings, the closest model to that reported in the literature $(2,11,16)$. The largest MI suggests that the item 'Turns on the TV to take my mind off the pain' should also load on the distractive responses factor. The factorial correlation coefficients between the factors were moderate to high (range of absolute values between 0.363 and 0.925). Questioning the distinction between the solicitous responses and distractive responses factors in this version could have been statistically justified because the factorial correlation coefficients exceeded 0.9. However, the factors obtained sufficiently high alpha coefficients (solicitous responses $=0.842$ and distractive responses $=0.700$ ) to suggest that each of these factors has a discriminating potential. Moreover, qualitative analysis of the items allows for the observation of an important theoretical and clinical distinction between these two factors that would be lost if they were grouped together.

The Cronbach alpha coefficients were moderate to high. For the unidimensional solution with 12 items, the alpha was computed to be 0.764 . For the negative responses factor, the alpha was 0.914 , for the solicitous responses factor, the alpha was 0.842 and for the distractive responses factor, the alpha was 0.700 . 
The fit indexes suggested that the three-factor oblique models (with or without crossloadings) were acceptable. In this case, it is customary to choose the most parsimonious one - the model without crossloadings. The NFI and NNFI were above 0.9 and the standardized RMR was 0.23 . For section 2 of the IMD, the items 'Ignores me' and 'Reads to me' were removed and a three-factor solution was suggested.

\section{FAs on IMD section 3}

The exploratory FA indicated that, in a four-factor oblique solution, two of the 18 items had low but not critical communalities ('Play cards or other games' had a communality of 0.122 and 'Take a trip' had a communality of 0.204 ). This solution explained $44 \%$ of the common variance. The items 'Play cards or other games', 'Visit friends' and 'Visit relatives' showed a tendency to group themselves with activities away from home factor items rather than items loading on the social activities factor. The presence of four distinct factors was doubtful in the exploratory FA, considering that only the item 'Go to a park or beach' loaded significantly on the fourth factor, and only explained $3 \%$ of the variation.

In the four-factor oblique solution obtained in LISREL, only the item 'Play cards or other games' could be considered as having a relatively low $\mathrm{R}^{2}(0.142)$. Considering the MIs, it was appropriate to add a factor loading between the activities away from home factor and the item 'Play cards or other games'. The factorial correlation coefficients between the factors were relatively high (range of absolute values between 0.573 and 0.992 ). In line with other articles about translating the MPI $(2,12,18)$, the distinction between the social activities and activities away from home factors was questioned because the factorial correlation coefficient between the factors was so high $(r=0.992)$, and because there was no clinical or theoretical argument strong enough in the context to support the distinction between these two factors.

Another series of confirmatory FAs was therefore conducted to check the fit of a three-factor oblique model. In this threefactor oblique solution, the item 'Play cards or other games' has a $\mathrm{R}^{2}$ of 0.181 , slightly higher than in the previous model. Table 3 shows the confirmatory FA factor loadings for the oblique three-factor model. The MIs indicated that a crossloading should be considered between the item 'Help with the house cleaning' and the outdoor work factor, as well as between the item 'Play cards or other games' and the household chores factor (which is not theoretically valid). The factorial correlation coefficients between the factors were moderate to high (range of absolute values between 0.680 and 0.759).

The Cronbach alpha coefficients were moderate to high. For the 18 items together, the alpha was computed to be 0.840 . For the household chores factor, the alpha was 0.812 . For the outdoor work factor, the alpha was 0.780 ; for the third factor in the four-factor solution (activities away from home), the alpha was 0.649; and for the social activities factor, the alpha was 0.643 . When grouping the last two factors to create the leisure activities factor, as described in the literature $(2,12,18)$, better results were obtained with the new factor, with alpha at 0.767 (and 0.777 if item 4 was removed from the combined factor).

The fit of the four oblique models (four factors with or without crossloading, three factors with or without crossloadings) compared in this section was satisfactory. The simplest model
TABLE 3

Item composition of the Inventaire multidimensionnel de la douleur, section 3, with factor loading

\begin{tabular}{|c|c|c|}
\hline \multirow{2}{*}{$\begin{array}{l}\text { Factors and items } \\
\text { General activity }(1.97 \pm 0.88, \alpha=0.840)\end{array}$} & \multicolumn{2}{|c|}{ Factor loading* } \\
\hline & & \\
\hline \multicolumn{3}{|l|}{ Household chores $(2.99 \pm 1.49, \alpha=0.812)$} \\
\hline Wash dishes. Laver la vaisselle. & 0.596 & $(0.552)$ \\
\hline Go grocery shopping. Faire le marché. & 0.652 & $(0.687)$ \\
\hline $\begin{array}{l}\text { Help with the house cleaning. Aider à faire le } \\
\text { ménage. }\end{array}$ & 0.949 & $(0.967)$ \\
\hline Prepare a meal. Préparer un repas. & 0.742 & $(0.746)$ \\
\hline Do a load of laundry. Faire la lessive. & 0.595 & $(0.545)$ \\
\hline \multicolumn{3}{|l|}{ Outdoor work $(0.84 \pm 1.03, \alpha=0.780)$} \\
\hline Mow the lawn. Tondre le gazon. & 0.503 & $(0.538)$ \\
\hline Work in the garden. Jardiner. & 0.436 & $(0.461)$ \\
\hline Work on the car. Entretenir la voiture. & 0.851 & $(0.842)$ \\
\hline Wash the car. Laver la voiture. & 0.962 & $(0.942)$ \\
\hline $\begin{array}{l}\text { Work on a needed house repair. Effectuer les } \\
\text { réparations qui s'imposent dans la maison. }\end{array}$ & 0.567 & $(0.541)$ \\
\hline \multicolumn{3}{|l|}{ Leisure activities $(2.03 \pm 1.02, \alpha=0.767)$} \\
\hline \multicolumn{3}{|l|}{ Activities away from home $(\alpha=0.649)$} \\
\hline $\begin{array}{l}\text { Go out to eat. Manger à l'extérieur (au } \\
\text { restaurant, chez des amis, etc). }\end{array}$ & 0.799 & $(0.911)$ \\
\hline Go to a movie. Aller au cinéma. & 0.513 & $(0.493)$ \\
\hline $\begin{array}{l}\text { Take a ride in a car. Faire une ballade en } \\
\text { voiture. }\end{array}$ & 0.486 & $(0.505)$ \\
\hline $\begin{array}{l}\text { Take a trip. Quitter la maison pour quelques } \\
\text { jours. }\end{array}$ & 0.379 & $(0.386)$ \\
\hline \multicolumn{3}{|l|}{ Social activities ( $\alpha=0.643$ ) } \\
\hline $\begin{array}{l}\text { Play cards or other games. Jouer aux cartes } \\
\text { ou à d'autres jeux. }\end{array}$ & 0.142 & $(0.181)$ \\
\hline Visit friends. Rendre visite à des amis. & 0.614 & $(0.636)$ \\
\hline $\begin{array}{l}\text { Visit relatives. Visiter des membres de la } \\
\text { famille. }\end{array}$ & 0.756 & $(0.792)$ \\
\hline $\begin{array}{l}\text { Go to a park or beach. Aller au parc ou au } \\
\text { bord de l'eau. }\end{array}$ & 0.670 & $(0.595)$ \\
\hline
\end{tabular}

$\overline{\text { Factor scores presented as mean } \pm S D \text {. }{ }^{*} \text { The factor loadings in parentheses }}$ correspond to the three-factor model where the items from the activities away from home and social activities factors were merged into one leisure activities factor

(the one with three oblique factors and without crossloadings) should be considered. Moreover, the internal consistency of the three-factor solution was better than each of the two original factors with which it was composed. The NFI and NNFI were above 0.9. The standardized RMR was 0.22 , and only changed by \pm 0.01 between the three- and four-factor oblique solutions.

Because it is common to use unifactorial scoring in this section for cluster purposes (19), the unifactorial model was evaluated. In fact, the unifactorial model had reasonable fit and internal consistency. The communalities of all 18 items were above 0.19 , internal consistency was 0.84 and the fit indexes exceeded 0.88 . The ease of use of a unifactorial solution could therefore be justified. For section 3 of the IMD, no items were removed and a three-factor solution was suggested.

\section{Comparison of the correlational structure}

To compare the correlation matrix among the various versions of the MPI, the correlation coefficients for the American, German and Dutch versions given in the article by Lousberg et 
TABLE 4

Interfactor correlations from the American, German-, Dutch- and French-speaking samples

\begin{tabular}{|c|c|c|c|c|c|c|c|c|c|}
\hline & & PI & $\mathrm{s}$ & PS & LC & $A D$ & NR & SR & DR \\
\hline \multirow[t]{4}{*}{ S } & a & 0.090 & & & & & & & \\
\hline & b & 0.340 & & & & & & & \\
\hline & c & 0.220 & & & & & & & \\
\hline & $d$ & 0.067 & & & & & & & \\
\hline \multirow[t]{4}{*}{ PS } & a & 0.580 & 0.050 & & & & & & \\
\hline & b & 0.680 & 0.290 & & & & & & \\
\hline & c & 0.560 & 0.230 & & & & & & \\
\hline & $d$ & 0.587 & 0.131 & & & & & & \\
\hline \multirow[t]{4}{*}{ LC } & a & -0.150 & 0.060 & -0.160 & & & & & \\
\hline & b & -0.180 & 0.230 & -0.130 & & & & & \\
\hline & c & -0.270 & 0.070 & -0.320 & & & & & \\
\hline & $d$ & -0.304 & 0.124 & -0.243 & & & & & \\
\hline \multirow[t]{4}{*}{$A D$} & a & 0.260 & -0.030 & 0.340 & -0.520 & & & & \\
\hline & b & 0.440 & 0.060 & 0.330 & -0.520 & & & & \\
\hline & c & 0.410 & -0.050 & 0.400 & -0.570 & & & & \\
\hline & $d$ & 0.439 & -0.031 & 0.327 & -0.446 & & & & \\
\hline \multirow[t]{4}{*}{ NR } & a & 0.000 & -0.380 & 0.030 & -0.140 & 0.200 & & & \\
\hline & b & 0.250 & -0.230 & 0.110 & -0.240 & 0.280 & & & \\
\hline & c & 0.240 & -0.340 & 0.120 & -0.220 & 0.320 & & & \\
\hline & $d$ & 0.218 & -0.190 & 0.092 & -0.153 & 0.249 & & & \\
\hline \multirow[t]{4}{*}{$\mathrm{SR}$} & a & 0.340 & 0.560 & 0.310 & -0.080 & 0.040 & 0.040 & & \\
\hline & b & 0.240 & 0.660 & 0.170 & 0.170 & 0.010 & -0.290 & & \\
\hline & c & 0.230 & 0.650 & 0.240 & 0.020 & 0.070 & -0.160 & & \\
\hline & $d$ & 0.267 & 0.668 & 0.342 & -0.038 & 0.156 & -0.218 & & \\
\hline \multirow[t]{4}{*}{ DR } & a & 0.100 & 0.420 & 0.050 & 0.110 & -0.010 & -0.010 & 0.490 & \\
\hline & $b$ & 0.340 & 0.490 & 0.310 & 0.050 & 0.160 & -0.020 & 0.400 & \\
\hline & c & 0.170 & 0.440 & 0.150 & 0.050 & 0.050 & -0.130 & 0.530 & \\
\hline & $d$ & 0.097 & 0.540 & 0.236 & 0.040 & 0.084 & -0.204 & 0.661 & \\
\hline \multirow[t]{4}{*}{ GA } & a & -0.220 & -0.120 & -0.170 & 0.190 & -0.100 & -0.080 & -0.180 & 0.080 \\
\hline & $b$ & -0.070 & 0.060 & -0.050 & 0.090 & 0.020 & -0.050 & 0.090 & 0.180 \\
\hline & c & -0.210 & -0.100 & -0.130 & 0.140 & -0.130 & -0.040 & 0.020 & 0.080 \\
\hline & $d$ & -0.471 & 0.027 & -0.282 & 0.183 & -0.238 & -0.059 & -0.081 & 0.010 \\
\hline
\end{tabular}

a American sample $(n=120), b$ German-speaking sample ( $n=185), c$ Dutchspeaking sample ( $n=733), d$ French-speaking sample $(n=227)$. AD Affective distress; DR Distractive responses; GA General activity; LC Life control; NR Negative responses; PI Pain interference; PS Pain severity; S Support; SR Solicitous responses

al (2) were compared with the correlation coefficients obtained with the IMD. Table 4 gives the Pearson correlation coefficients computed among the scores on each factor. The score for each factor was obtained by averaging the item scores according to the original factor structure; ie, no items were omitted or used more than once. If there were missing values for one or more items in the factor, that item was omitted and the score was computed with the rest of the items. There was no case in this dataset in which the number of missing item values exceeded the number of valid answers for each factor.

Visual assessment of the coefficients in Table 4 reveals a definite similarity between the intercorrelations of the different instruments. Similar to Lousberg et al (2), high intercorrelations for the factor pairs pain severity - pain interference, life control - affective distress, and support - solicitous responses were observed, as well as between the solicitous responses and distractive responses factors. In addition, intercorrelations higher than those observed with the other instruments for the following intercorrelations were noted: solicitous responses affective distress $(\mathrm{r}=0.156)$, affective distress - general activity $(\mathrm{r}=-0.238)$ and pain interference - general activity $(\mathrm{r}=-0.471)$.

\section{DISCUSSION}

Generally speaking, the IMD has good psychometric properties. It behaved very similarly to the original tool (1) and to other translations of the MPI $(2,11,12)$, and the factors' intercorrelation coefficients were comparable with the different versions of the MPI. However, the statistical analyses pinpointed items or factors requiring discussion.

In the assessment of the experience of pain (section 1), the five-factor structure is maintained. The correlation between the pain interference and pain severity scales is high $(\mathrm{r}=0.59)$ and the arguments put forward by Lousberg et al (2) also apply here. It is hardly surprising to find a strong correlation between the pain interference and pain severity factors. For most people living with chronic pain, subjectively speaking, the severity of the pain explains their incapacity or the extent to which the pain interferes with certain activities. However, because certain individuals report a high degree of pain severity but a low degree of pain interference or vice versa, we have to distinguish between pain and disability (20). Combining these two scales in a pain severity/interference scale would obscure the clinically useful distinction between pain and disability.

Moreover, a number of studies (21) have reported clinical results using a five-factor factorial structure, with versions of the MPI in different languages. Cluster profiling proposed by Rudy et al (22) is widely used $(6,23-27)$ and implements the five factors in section 1 to categorize individuals based on a biopsychosocial perspective. Because replicating these findings would be of interest, retaining a five-factor structure seems meaningful because it conforms with what is reported in the literature on the MPI. It should be mentioned that this cluster profiling (dysfunctional, interpersonally distressed, adaptive coper) is widely used with the MPI and could be used with the IMD, using French-language sample results for the clustering.

Specifically, the results for section 1 of the IMD indicated that an item did not fit well in any of the specific underlying factors for this population. As noted earlier, the item 'How worried is your spouse [...]' is different from the two other items making up this factor. Unlike the items 'How supportive or helpful is your spouse (significant other) to you in relation to your pain?' and 'How attentive is your spouse (significant other) to you because of your pain?', the item 'How worried is your spouse [...]' refers to the feelings (worry) of the spouse (significant other). It therefore appears that this item, which introduces the interpretation of someone else's feelings (by asking respondents to rate the degree of worry experienced by their significant others), is actually touching on a concept other than support, namely the spouse's anxiety about their partner's pain. This concept, which could probably be the topic of a separate assessment, strays from the factor 'Support from 
significant other' and also stands apart in that it asks for an opinion about someone else's feelings. The statistical analyses show that this item was not strongly linked to the other two items in the factor. Because removing this item meant that the scale obtained better statistical results and seemed to refer to another concept, the item 'How worried is your spouse [...]' was withdrawn from the IMD.

In section 1, we also found that the items 'How much has your pain changed your marriage and other family relationships?' and 'How much has your pain changed your friendships with people other than your family?' tended to group with the affective distress factor rather than the pain interference factor. Both of these items, compared with the others in the pain interference factor, allude to relationship difficulties (marriage, family and friendship relationships) associated with the issue of pain. It may be that, for the respondents in this sample living with persistent pain, poor quality of interpersonal relations is more closely associated with affective distress. This is not surprising given that in a chronic pain condition, the poor quality of interpersonal relations is often an indicator of psychological difficulties (28). It should be noted that structural differences can be associated with intercultural differences. Some societies may be focused more on the individual well-being in a family unit, whereas others favour the well-being of the family unit over the well-being of each individual. Therefore, the perception of the feelings of others as well as the actual feelings of significant others will differ.

Although these two items ('How much has your pain changed your marriage and other family relationships? and 'How much has your pain changed your friendships with people other than your family?') have a tendency toward the affective distress factor, they play an important role in the construction of the pain interference factor because they ask directly for an evaluation of changes in life habits. In that matter, the pain interference factor has good statistical properties and changing the items would not be appropriate.

Weak correlations were observed between the support factor and the other factors in section 1. Support clearly stands apart from the other factors in this section, which make no reference to other people. The support factor in section 1 is closer to the three factors in section 2 that evaluate the spouse's reactions to the respondent's pain from the respondent's standpoint. Thus, the support factor and the whole of section 2 allude to the way the spouse (or significant other) reacts to the respondent's pain. Moreover, in the results of the confirmatory FAs on the whole questionnaire of the original English version of the MPI, Deisinger et al (17) reported that the support factor related more to section 2 of the MPI than to section 1 . However, the authors of the original tool appear to have deliberately incorporated an interpersonal component in section 1 , which evaluates the experience of pain. Whether an individual feels supported by their significant other is an integral part of the experience of pain. Although the support scale has much to do with section 2 , it is important that it remains in section 1 to do justice to the conjugal problems that sometimes stem from living with chronic pain.

\section{Section 2}

The results showed that internal consistency of the negative responses factor in section 2 may be improved if the item 'Ignores me' was removed. In French, the item 'Ignores me' (Ne porte pas attention) contains a negative, which may cause confusion, particularly if the answer is 'Never' (Jamais), resulting in a double negative. However, in a number of previous translations into other languages, it was proposed that the item 'Ignores me' be removed from section 2 because it was not highly correlated with the negative responses factor $(2,10-12)$. The suggestion was therefore made to eliminate 'Ignores me' from section 2 of the IMD.

For the distractive responses factor, we observed that the alpha may be improved by removing the item 'Reads to me'. This item does not seem to be representative of distractive responses elicited by people living with chronic pain because the vast majority of participants in our sample $(72.2 \%)$ answered 'Never' to the item 'Reads to me'. Moreover, whether this item is sufficiently relevant to contemporary life is open to discussion; other translations have also left it out $(2,12)$. It was suggested that the item 'Reads to me' be omitted from section 2 of the IMD.

As mentioned in the Results section, statistically speaking, it was justified to question the distinction between the distractive responses and the solicitous responses factors in section 2 because we obtained a factorial correlation coefficient of 0.9. The three-factor structure obtained satisfactory statistical results both in regard to adjustment indexes (NFI and NNFI above 0.9) and internal consistency coefficients (Table 2). Moreover, merging solicitous responses and distractive responses into a single factor would obscure an important distinction between the two, whereas a qualitative analysis of the items showed that the items in distractive responses suggested a resumption of the respondent's usual activities, while the items in solicitous responses suggested an encouragement of passivity in managing pain. Although these factors were similar to each other in alluding to positive responses by the spouse (compared with negative responses), they are clinically and theoretically very different (29). Clinicians and researchers in the field of pain management need to distinguish between what encourages people to resume their normal activities and what encourages sedentariness in pain management. Creating a single positive responses factor would eliminate the distinction between encouraging the resumption of usual activities and encouraging passivity in managing pain.

\section{Section 3}

For section 3, we suggest using a three-factor structure that combines the social activities and activities away from home scales into a single leisure activities scale. This factorial grouping obtains better results, statistically speaking, and is theoretically very sound; grouping all leisure activities together is also reasonable. This grouping is found in other translations of the MPI $(2,11)$. Removing the item 'Play cards or other games' from section 3 would have a minor statistical impact (alpha increasing from 0.767 to 0.777 ). On the other hand, from a clinical standpoint, such an item clearly alludes to the concept evaluated by the new scale (leisure activities); we therefore suggest retaining all items in section 3 of the IMD. In addition, statistical findings show that using a factor that evaluates the general activity level, including all the items in section 3, is also acceptable. Many studies $(30,31)$ use a general activity factor comprising all of the items rather than the subscales in this section. The profiling of persons living with chronic pain, 
therefore, takes into account only the general activity factor (19), which provides some insight into the overall degree of activity.

\section{Intercorrelations}

Certain factors were found to correlate more closely than observed with the original tool and other translations (2). As expected, we noted a strong inverse correlation between the general activity and pain interference factors - a high degree of pain interference was associated with a low activity level. Analysis of pain interference items revealed a reference to various areas of activity (family, social and work) that can be adversely affected by pain. The affective distress - general activity link is interesting; as expected, withdrawal from usual activities is directly associated with an increase in emotional problems. Moreover, resumption of usual activities is often prescribed not only combat the person's depression, but also to target psychological problems associated with persistent pain (32). The solicitous responses - affective distress link is intriguing because receiving attentive responses from the spouse is associated with greater emotional distress in respondents. This may mean that the more an individual living with chronic pain perceives their significant other as being solicitous and attentive regarding their condition, the more they feel they are a burden to their spouse and immediate circle. It is easy to imagine how perceiving themselves as a burden to others can affect a person's self-esteem and affective distress. Moreover, as mentioned earlier, the items in the solicitous responses factor encourage a passive approach to dealing with pain. Encouraging sedentariness in this way may well be associated with more severe emotional distress.

Also noted was a vicious circle of high pain interference low general activity - high affective distress. Various hypotheses may be suggested to explain a causal link between the various factors. However, the degree of activity is clearly central to this cycle. Focusing on the degree of activity could help to attain various targets, not only in terms of pain, but also in regard to affective distress (32).

\section{CONCLUSION}

The IMD has a factorial structure comparable with that of the MPI (1) and validated translations $(2,11,12)$. Although eliminating the item 'How worried is your spouse [...]' from section 1 and two items from section 2 ('Ignores me' and 'Reads to me') may affect the descriptive scores of the IMD compared with those of another version, it does not affect the factorial structure. However, although all the items were retained in section 3 of the IMD, a three-factor structure (or a unifactorial correction) is preferred. The chief objective of the present study was to offer clinicians and researchers evaluating pain a French-language version of the MPI (see <http://www.luciebruneau.qc.ca $>$ under the Documentation subsection for a PDF version, or contact the corresponding author) with good psychometric properties. The IMD now has to be tested for temporal stability and sensitivity to treatments. The tool should also be used with a variety of populations living with pain.

ACKNOWLEDGEMENTS: The authors would like to thank Adèle Karamanoukian and Sophie Michaud for their help in the translation process. This work has been supported by the Centre for Interdisciplinary research in Rehabilitation of Greater Montreal, Centre de réadaptation Lucie-Bruneau site. Portions of this project were presented at the Annual meeting of the Canadian Pain Society, Halifax, 2005, and at the Congrès de traumatologie, Montreal, 2005.

\section{REFERENCES}

1. Kerns RD, Turk DC, Rudy TE. The West Haven-Yale Multidimensional Pain Inventory (WHYMPI). Pain 1985;23:345-56.

2. Lousberg R, Van Breukelen GJ, Groenman NH, Schmidt AJ, Arntz A, Winter FA. Psychometric properties of the Multidimensional Pain Inventory, Dutch language version (MPI-DLV). Behav Res Ther 1999;37:167-82.

3. Walter L, Brannon L. A cluster analysis of the Multidimensional Pain Inventory. Headache 1991;31:476-9.

4. Broderick JE, Junghaenel DU, Turk DC. Stability of patient adaptation classifications on the Multidimensional Pain Inventory. Pain 2004;109:94-102.

5. Olsson I, Bunketorp O, Carlsson SG, Styf J. Prediction of outcome in whiplash-associated disorders using West Haven-Yale Multidimensional Pain Inventory. Clin J Pain 2002;18:238-44.

6. Zaza C, Reyno L, Moulin DE. The Multidimensional Pain Inventory profiles in patients with chronic cancer-related pain: An examination of generalizability. Pain 2000;87:75-82.

7. Beck JG, Chase TJ, Berisford MA, Taegtmeyer H. Pain profiles of patients with nonorganic chest pain: A preliminary report of the Multidimensional Pain Inventory. J Pain Symptom Manage 1992; 7:470-7.

8. Turk DC, Monarch ES, Williams AD. Assessment of chronic pain sufferers. In: Hadjistavropoulos HD, Craig KD, eds. Pain: Psychological Perspectives. Mahwah: Lawrence Erlbaum Associates, 2004:209-43.

9. Bradley LA, McDonald Haile J, Jaworski TM. Assessment of psychological status using interviews and self-report instruments. In: Turk DC, Melzack R, eds. Handbook of Pain Assessment. London: The Guilford Press, 1992:193-213.

10. Flor H, Rudy TE, Birbaumer N, Streit B, Schugens MM. [The applicability of the West Haven-Yale multidimensional pain inventory in German-speaking countries. Data on the reliability and validity of the MPI-D.] Schmerz 1990;4:82-7.

11. Ferrari R, Novara C, Sanavio E, Zerbini F. Internal structure and validity of the Multidimensional Pain Inventory, Italian language version. Pain Med 2000;1:123-30.

12. Bergstrom G, Jensen IB, Bodin L, Linton SJ, Nygren AL, Carlsson SG. Reliability and factor structure of the Multidimensional Pain Inventory - Swedish Language Version (MPI-S). Pain 1998;75:101-10.

13. Vallerand RJ. Vers une méthodologie de validation trans-culturelle de questionnaires psychologiques: Implications pour la recherche en langue française. Can Psychol 1989;30:662-80.

14. Jöreskog KG, Sörbom D. LISREL 8: User's Reference Guide, 2nd edn. Lincolnwood: Scientific Software, 1993:1-378.

15. Marsh H, Balla J, McDonald R. Goodness-of-fit-indexes in confirmatory factor analyses: The effect of sample size. Psych Bull 1988; 103:391-410.

16. Bergstrom KG, Jensen IB, Linton SJ, Nygren AL. A psychometric evaluation of the Swedish version of the Multidimensional Pain Inventory (MPI-S): A gender differentiated evaluation. Eur J Pain 1999;3:261-73.

17. Deisinger JA, Cassisi JE, Lofland KR, Cole P, Bruehl S. An examination of the psychometric structure of the Multidimensional Pain Inventory. J Clin Psychol 2001;57:765-83.

18. Bernstein IH, Jaremko ME, Hinkley BS. On the utility of the West Haven-Yale Multidimensional Pain Inventory. Spine 1995;20:956-63. 
19. Rudy TE, Turk DC, Zaki HS, Curtin HD. An empirical taxometric alternative to traditional classification of temporomandibular disorders. Pain 1989;36:311-20

20. Waddell G. The Back Pain Revolution. New York: Churchill Livingstone, 1998:xi-438.

21. Turk DC. Customizing treatment for chronic pain patients: Who, what, and why. Clin J Pain 1990;6:255-70.

22. Rudy TE. Multiaxial Assessment of Pain: Multidimensional Pain Inventory Computer Program Users' Manual, Version 2.1. Pittsburgh: Pain Evaluation and Treatment Institute, 1989.

23. Soderlund A, Denison E. Classification of patients with whiplash associated disorders (WAD): Reliable and valid subgroups based on the Multidimensional Pain Inventory (MPI-S). Eur J Pain 2006;10:113-9.

24. Epker J, Gatchel RJ. Coping profile differences in the biopsychosocial functioning of patients with temporomandibular disorder. Psychosom Med 2000;62:69-75.

25. Lousberg R, Groenman N, Schmidt A. Profile characteristics of the MPI-DLV clusters of pain patients. J Clin Psychol 1996;52:161-7.

26. Gatchel RJ, Noe CE, Pulliam C, et al. A preliminary study of Multidimensional Pain Inventory profile differences in predicting treatment outcome in a heterogeneous cohort of patients with chronic pain. Clin J Pain 2002;18:139-43.

27. Okifuji A, Turk DC, Eveleigh DJ. Improving the rate of classification of patients with the Multidimensional Pain Inventory (MPI): Clarifying the meaning of "significant other". Clin J Pain 1999;15:290-6.

28. Leonard MT, Cano A, Johansen AB. Chronic pain in a couples context: A review and integration of theoretical models and empirical evidence. J Pain 2006;7:377-90.

29. Schwartz L, Jensen MP, Romano JM. The development and psychometric evaluation of an instrument to assess spouse responses to pain and well behavior in patients with chronic pain: The Spouse Response Inventory. J Pain 2005;6:243-52.

30. Turk DC, Rudy TE. Toward an empirically derived taxonomy of chronic pain patients: Integration of psychological assessment data. J Consult Clin Psychol 1988;56:233-8.

31. Rudy TE, Kubinski JA. Program evaluation methods for documenting pain management effectiveness. In: Gatchel RJ, Turk DC, eds. Psychological approaches to pain management: A practitioner's handbook. New York: Guilford Press, 1996:486-505.

32. Sullivan MJ, Stanish WD. Psychologically based occupational rehabilitation: The Pain-Disability Prevention Program. Clin J Pain 2003;19:97-104 


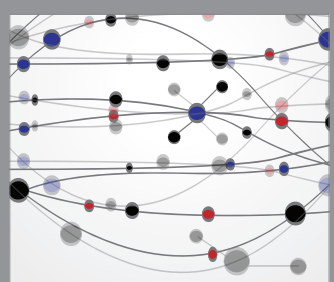

The Scientific World Journal
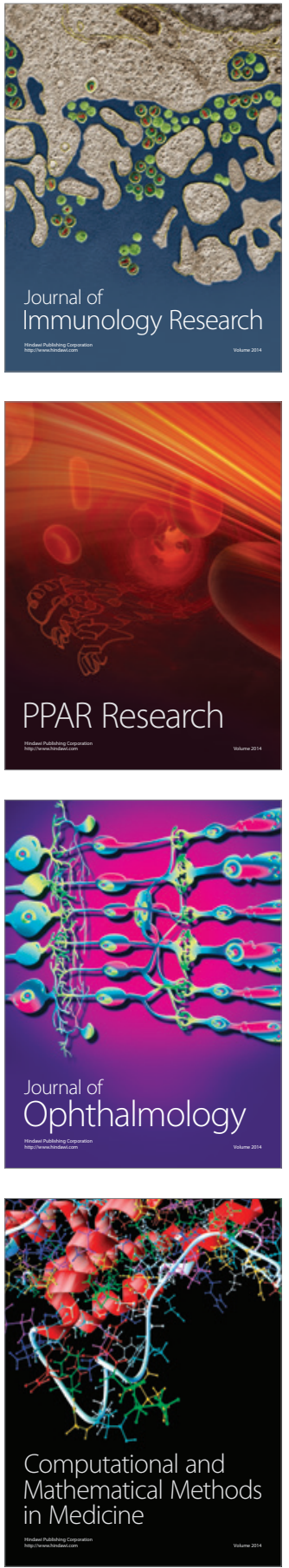

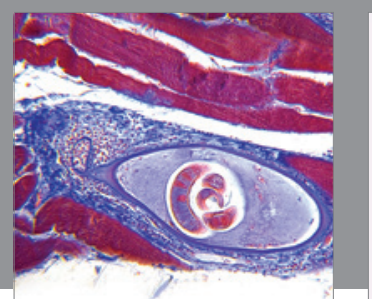

Gastroenterology Research and Practice

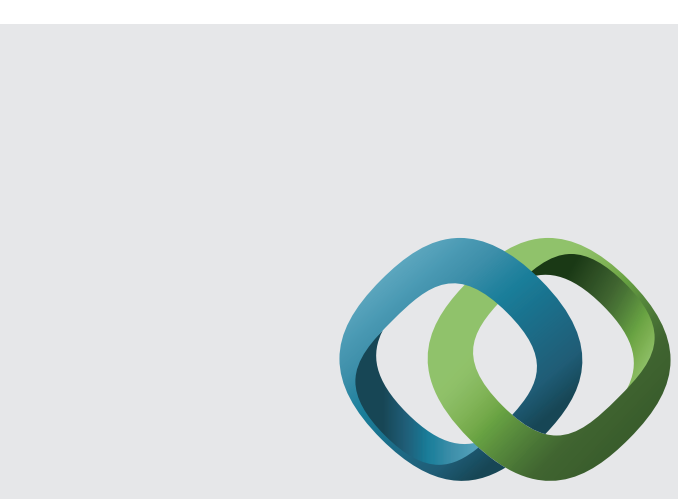

\section{Hindawi}

Submit your manuscripts at

http://www.hindawi.com
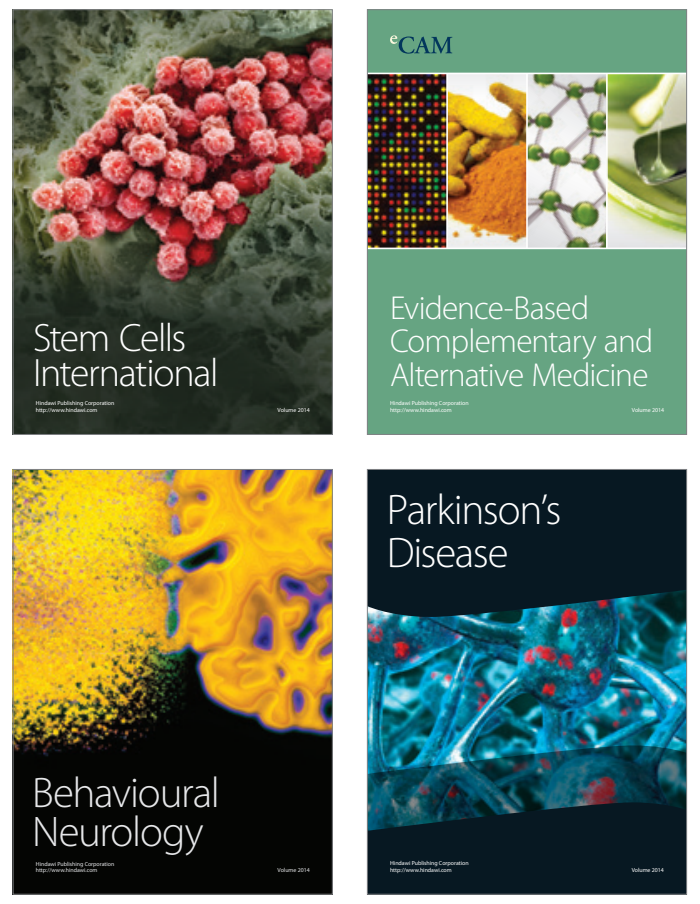
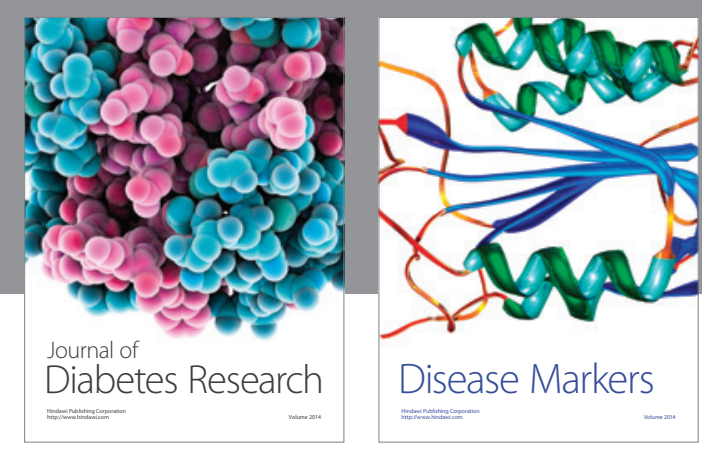

Disease Markers
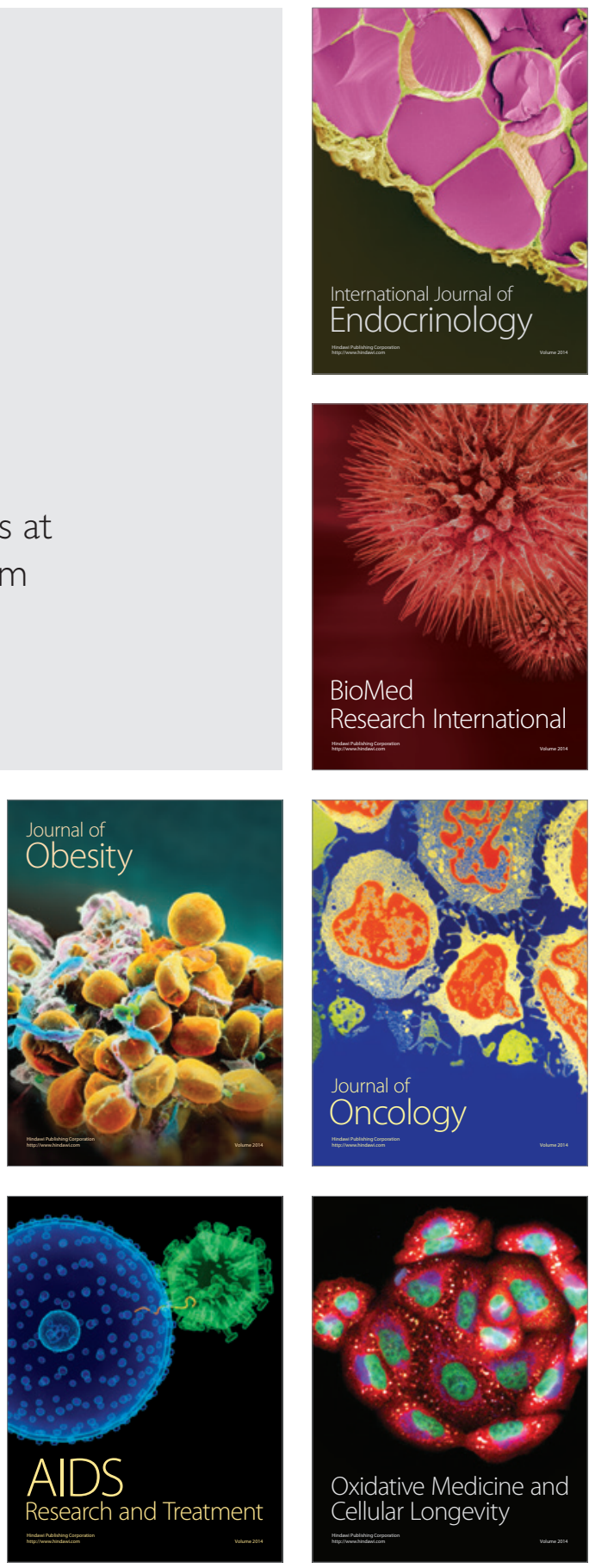